\title{
LA NUEVA NARRATIVA DEL TERRORISMO INTERกACIONAL EN ÁFRICA: RESPUESTAS Y RESULTADOS
}

\author{
The new narrative of International Terrorism in \\ Africa: Ansuers and Impact
}

Bajo el paradigma de las "nuevas guerras", los conflictos armados contemporáneos en el continente africano fueron despojados de los fines políticos e ideológicos, para explicar las motivaciones de los actores beligerantes principalmente en base a la avaricia económica y a las rivalidades identitarias. Tras los atentados del 11-S ha ido cogiendo forma una narrativa que de forma específica ha puesto en el centro el fenómeno de la violencia extremista y el terrorismo internacional en el continente africano. Este diagnóstico ha generado el despliegue en diversos puntos del continente de diferentes estrategias antiterroristas, tanto de carácter regional como internacional. En el presente artículo dibujaremos un mapa de la considerada violencia extremista presente actualmente en algunas regiones del continente, así como de las estrategias antiterroristas desplegadas, para analizar sus resultados, validar o no el diagnóstico de esta narrativa y confrontarlo con otras miradas. 
Under the "new wars" paradigm, contemporary armed conflicts in the African continent have been stripped of their political and ideological dimension, and the motivations of the actors involved have been reduced to economic greed and identity rivalries. After the attacks of 9/11, a narrative has appeared focusing on extremist violence and international terrorism in the African continent. This diagnosis has triggered the deployment in different parts of the continent of different antiterrorist strategies, both regional and international. In the present article we will draw a map of this extremist violence, present nowadays in some regions of the continent, along with the anti-terrorist strategies deployed, in order to analyse their impact, to validate or deny the diagnosis of this narrative and to confront it to other views.

\section{Introducción}

A partir del fin de la Guerra Fría se ha desarrollado una ingente literatura, en el marco de lo que la politóloga Mary Kaldor (2001) acuñó como "nuevas guerras", que ha puesto el foco en tratar de comprender las identificadas como nuevas causas y naturaleza de la conflictividad armada contemporánea, que ha tenido un gran impacto en la forma de entender e interpretar la conflictividad armada en el contexto africano. Desde estas nuevas miradas, que han resaltado por centrarse en proporcionar explicaciones monocausales a las raíces de la violencia, se ha ido evolucionando desde un discurso de carácter más etnicista-identitario, enmarcado en la tesis del "nuevo barbarismo" (Kaplan, 1994), donde se percibían las guerras como sinónimo de luchas étnicas entre pueblos; pasando por las que han resaltado el subdesarrollo y la pobreza como el "germen" donde se explica la violencia en el continente (Duffield, 2001); a las llamadas "guerras de la oportunidad" o de la codicia (greed), que enfatizan el papel de los recursos naturales en la génesis de los conflictos armados (Collier y Hoeffler, 2004); hasta llegar a las tesis que pusieron el acento en los Estados fallidos o colapsados para explicar el estallido de la guerra (Di John, 2010; Milliken y Krause, 2002). Vinculada a esta última literatura, tras los atentados del 11-S ha ido cogiendo forma una narración que, de forma específica ha puesto en el centro el fenómeno de la violencia extremista y el terrorismo internacional ${ }^{1}$, rescatando a su vez los principios que sustentaron la narrativa del "nuevo barbarismo", el carácter de guerras religiosas o identitarias.

La conflictividad armada presente en el continente africano, de acuerdo con esta narrativa, se desarrolla fundamentalmente en el marco de Estados con presuntamente poca o nula capa-

1 Probablemente pocos conceptos son tan controvertidos como el que implica el de "terrorismo". No existe, ni ha existido, una definición consensuada en la academia, ni en los organismos internacionales, sobre el término, lo cual dificulta enormemente su estudio comparativo y sus aproximaciones. De esta forma, el concepto de "terrorismo" se conforma como una idea muy controvertida, basada normalmente en asunciones de carácter político que buscan legitimar o deslegitimar una serie de políticas o actores. En el presente artículo, y debido a que presentamos las aproximaciones que se han hecho del fenómeno en el continente africano, utilizamos el concepto en su acepción más hegemónica que resalta el carácter indiscriminado de la violencia con objetivos políticos. Ello no equivale a afirmar que estamos de acuerdo con esta definición ni con las supuestas causas de su origen que esboza esta literatura. Para un mayor detalle sobre este debate véase al respecto: Bruce, G. (2013). Definition of Terrorism Social and Political Effects. Journal of Military and Veterans' Health, 21(2), 26-30; Melo, P. A. (2010). In search of new wars: The debate about a transformation of war. European Journal of International Relations, 16; Rapoport, D. C. (Ed.). (2006). Terrorism. Critical Concepts in Political Science. Routledge; Schmid, A. P. (2004). Frameworks for conceptualising Terrorism. Terrorism and Political Violence, 16(2); Schmid, A. P., Jongman, A. J. et al. (1988). Political terrorism: A new guide to actors, authors, concepts, data bases, theories and literature. Transaction Books New Brunswick, NJ.; Tilly, C. (2004). Terror, Terrorism, Terrorist. Sociological Theory, 22(1), 5-13. 
cidad de respuesta, estructuras incapaces para enfrentar este fenómeno, y basado en odios y tensiones religiosas, así como en luchas identitarias. La presencia destacada de elementos religiosos en diferentes conflictos armados (Nigeria, Sahel, Somalia, R. Centroafricana, Uganda, Somalia, etc.) ha servido para que vuelva a emerger la catalogación de conflictos de base "religiosa” (religious wars) (Rapoport, 2002), fundamentalistas, yihadistas ${ }^{2}$ o islamistas radicales ${ }^{3}$. En ellos se resalta el papel criminal de las rebeliones, así como en algunas de ellas también del Estado, tachándolas de actos de carácter delictivo, indiscriminados y dirigidos mayoritariamente contra la población civil, que buscan sembrar el terror en las sociedades, de ahí su etiqueta como actos terroristas. A su vez, el nuevo marco internacional, generado a raíz de la ocupación estadounidense en Iraq y sus efectos en Oriente Medio, sumado posteriormente a las repercusiones de los estallidos de las conocidas como primaveras árabes, ha motivado la expansión del llamado "terrorismo transnacional" en diferentes puntos del continente africano, dibujado con la presencia de actores como el Estado Islámico de Iraq y Siria (ISIS) ${ }^{4}$ y Al Qaeda 5 .

En la actualidad, en el continente africano se identifica la presencia de, al menos, 13 conflictos armados (Escola de Cultura de Pau, 2017), de los cuales 6 destacan por la presencia de actores enmarcados en la categoría "yihadistas" (Libia, Argelia, Sahel, Lago Chad, Somalia y R. D. Congo este), mientras los otros 7 poseen otras características (Sudán -Darfur y Kordofan Sur y Nilo Azul-, Sudán del Sur, R. Centroafricana, Burundi, R. D. Congo y Etiopía). Este escenario dibuja un mapa donde se observan diferentes conflictos armados que sacuden la región central del continente, cuyas causas y dinámicas y, sobre todo, el despliegue de misiones de contención de paz, difieren ostensiblemente de las generadas en los escenarios de violencia en el África Occidental, la región del Magreb y el Cuerno de África.

\section{En la actualidad, en el continente africano se identifica la presencia de, al menos, 13 conflictos amados}

\section{El fenómeno del "terrorismo" en África}

El terrorismo, como conceptualización de la violencia, no ha sido un término que haya estado muy presente en los estudios sobre la conflictividad armada en el África subsahariana previos al 11-S. La terminología que alude a los movimientos armados africanos ha ido evolucionando con

2 El término "yihadista" proviene de la palabra "yihad" que en árabe se refiere al esfuerzo en el servicio de Dios. Gilles Kepel define "yihad" como el "esfuerzo para propagar el islam en uno mismo, en la sociedad o en el mundo con cualquier medio; 'guerra legal' o 'sagrada' contra los infieles prescrita por la sharía". El International Crisis Group ha rescatado la controversia que supone el uso del término "yihadista": "Muchos musulmanes encuentran que su uso en el contexto de la violencia política es impreciso y ofensivo. Reduce un concepto religioso complejo, que durante siglos ha tomado muchas formas, a menudo pacíficas, a la guerra. En opinión de la gran mayoría de los musulmanes, los "yihadistas" de hoy perturban los principios del islam". Muchas organizaciones armadas se identifican a sí mismas como "yihadistas", por lo que su empleo en este texto, aun a sabiendas de la controversia que comporta el mismo, se hace desde el propio etiquetado de estos grupos. Para mayor detalle sobre este debate véase: International Crisis Group (2016a, p. 2); Kepel (2000).

3 El término "islamista" hace alusión a aquellos grupos que de manera proactiva promueven o defienden la ideología islámica, leyes, políticas o costumbres en un estado o sociedad. De esta forma, los grupos islámicos violentos se distinguirían de otros grupos islámicos en el uso de la violencia como canal para conseguir sus resultados (Dowd, 2015, p. 507).

4 Existe una gran controversia en la denominación del grupo liderado por Abu Bakr al-Baghdadi, conocido como el Estado Islámico -Islamic State (IS)-, existiendo diferentes términos empleados para referirse a él: Estado Islámico de Iraq y Siria, en inglés Islamic State of Iraq and Syria (ISIS); Estado Islámico de Siria y el Levante, Islamic State of Iraq and the Levant (ISIL), o por su acrónimo en árabe al-Dawla al-Islamyia fil Iraq wa'al Sham (Daesh). En el presente documento, nos referiremos a él como el ISIS. Sobre las razones del debate sobre la denominación véase The Week UK, Islamic State, Daesh or Isis: the dilema of naming the militants. 13 de julio de 2015. Disponible en http://www.theweek.co.uk/isis/62422/islamic-state-daesh-or-isis-the-dilemma-of-naming-the-militants

5 Véase al respecto, por ejemplo: Núñez Villaverde, Hageraats, y Kotomska (2009); Cilliers (2015b). 
el paso del tiempo a medida que se fueron modificando las formas de las rebeliones, el contexto internacional y los discursos de los actores. De este modo, como subraya William Reno (2011, pp. 1-15), se ha pasado de la calificación de las rebeliones como "héroes nacionales", (década de los cincuenta), a la de "luchadores por la libertad" (décadas de los sesenta y setenta), "rebeldes reformistas" (década de los ochenta), a "señores de la guerra" o warlord (década de los noventa). En todas ellas, el uso del concepto "terrorismo" o "terroristas" para hacer alusión a los movimientos armados africanos ha sido, cuanto menos, marginal hasta principios del siglo XXI. Al respecto, los autores hacían uso de otra terminología para explicar el carácter de las guerras: bandidos sociales (Isaacman, 1977; Keller, 1973), insurgencias (Clapham, 1998), rebeliones (Reno, 2011), resistencias (Walraven y Abbink, 2008, p. 18) o guerrillas (Bøås y Dunn, 2007), entre las más destacadas. Ello llevó a que incluso la Organización para la Unidad Africana (OUA) y su sucesora Unión Africana (UA), remarcasen la necesidad de distinguir entre las luchas de liberación frente a la actividad terrorista, recalcando que "la lucha que las personas llevan a cabo de acuerdo con los principios del derecho internacional en pos de su liberación y autodeterminación, incluidas las luchas armadas frente al colonialismo, la ocupación, la agresión y la dominación a la que les someten fuerzas extranjeras no deben considerarse actos terroristas" (OAU, Convention on the Prevention and Combating of Terrorism, artículos 1.3 y 3 ).

Sin embargo, el cambio en el discurso se fue transformando en función de la nueva concepción sobre los objetivos, métodos e ideas que supuestamente movían a los movimientos armados, así como también por el contexto internacional. En la actualidad, y sobre todo a raíz de los atentados contra las Torres Gemelas, el discurso hegemónico ha desplazado los conceptos más politizados del siglo XX con la intención de negar las implicaciones ideológicas, empleando el término "terrorismo" para catalogar a todos los grupos que optan por la vía armada.

Jakkie Cilliers (2015a, p. 24), director del Institute for Security Studies defiende que, en relación a la violencia extremista islámica en la historia reciente del continente africano, podemos distinguir tres olas sucesivas que tuvieron su impacto sobre todo en el norte de África ${ }^{6}$. La primera de ellas se relaciona con la vuelta, a principios de la década de los noventa, de los excombatientes que lucharon en la guerra de Afganistán frente a la ocupación soviética y cuyos efectos se dejaron ver sobre todo en Argelia - con la emergencia de grupos armados como el Grupo Islámico Armado (GIA) - y Egipto ${ }^{7}$. Una segunda ola relacionada con la invasión estadounidense a Iraq en el año 2003, episodio que habría facilitado el reclutamiento de yihadistas provenientes de diversos países de la región y que sirvió para fortalecer a Al Qaeda, así como para promover el surgimiento posterior del ISIS. Finalmente, la tercera se relaciona con el impacto de la Primavera Árabe -originada en Túnez en el año 2010- en la región del Magreb, fundamentalmente a partir de la guerra en Libia y la caída del régimen de Gaddafi y su efecto en los países de la región (Cilliers, 2015a, p. 24; International Crisis Group, 2016a, p. 6).

Como parte del impacto de las primaveras árabes en el continente, el episodio de desestabilización más importante fue la caída del régimen de Gaddafi en 2011, que provocó un efecto bumerán en la región. En primer lugar, desencadenó la vuelta a Malí de los combatientes tua-

6 Un diagnóstico parecido es presentado por el International Crisis Group (2016a, pp. 5-6) "Exploiting Disorder: Al-Qaeda and the Islamic State”. Crisis Group Special Report.

7 Véase también Botha, A. (2008) “Terrorism in the Maghreb”, Institute for Security Studies, 144. Disponible en: www.issafrica.org/publications/monographs/terrorism-in-the-maghreb-the-transnationalisation-of-domesticterrorism

\section{Unión Africana (UA) remarca la necesidad de distinguir entre las luchas de liberación frente a la actividad} terrorista 
reg que habían combatido bajo las ordenes de Gaddafi, lo que dio pie al inicio de la rebelión en el norte de Malí, la proclamación unilateral de independencia de la región de Azawad por el Movimiento Nacional de Liberación de Azawad (MNLA) y el anuncio del nacimiento de la autodenominada República Islámica de Azawad el 6 de abril de 2012, regida por la sharía (Cilliers, 2015b, p. 19). Paralelamente, el caos generado por la desestabilización de Libia propició el surgimiento de numerosas milicias en el interior del país, pero también expandió la guerra a otros rincones, fundamentalmente a la región del Sahel, facilitando la entrada de ISIS en el continente africano (Cilliers, 2015b, p. 19; Turse, 2015, p. 29).

Paralelamente, a las revueltas en el mundo árabe se sumó la retirada de las tropas estadounidenses de Iraq, creando "un vacío de seguridad que propagó el ascenso del Estado Islámico a su actual preeminencia sobre Al Qaeda” (Cilliers, 2015a, p. 24). El surgimiento y la proliferación de ISIS habría alentado movimientos armados como el de Boko Haram, en busca del establecimiento de territorios similares "autónomos", algo que por otro lado ya estaba presente en África en las regiones del Sahel y en Somalia, bajo lealtades nominales de diferentes grupos, como $\mathrm{Al}$ Qaeda en el Magreb Islámico (AQMI) o al-Shabaab, hacia la red de Al Qaeda. Cilliers (2015a, pp. 29-30) manifestaba al respecto:

Desde 1989 el terrorismo en África constituye un componente relativamente pequeño de la actividad terrorista a nivel mundial [...]. Esto cambió en 2011 debido a la repercusión de acontecimientos en Nigeria, a causa de la inusitada brutalidad y los asesinatos generalizados perpetrados por Boko Haram. [... l la amenaza de al-Qaeda y del Estado Islámico se ha extendido a África de forma organizada y significativa [... . Los movimientos locales se alinean con el Estado Islámico o con al-Qaeda como parte de los esfuerzos para aumentar su alcance e influencia.

En este contexto, ambas organizaciones habrían tratado de explotar el desorden generado tras las revoluciones árabes para ampliar sus territorios, manteniendo un vis-à-vis para sumar nuevas alianzas en su estrategia por la yihad global, siendo África uno de los escenarios. (International Crisis Group, 2016; Sharif y Richards, 2016, p. 204). Al respecto, el Africa Center for Strategic Studies (2018) ha identificado seis diferentes categorías de grupos militantes islamistas presentes en el continente africano en la actualidad, donde todos ellos poseen alguna vinculación con alguna de las dos redes: Boko Haram, al-Shabaab, grupos vinculados a ISIS en el norte de África (Túnez y Libia), grupos afiliados Al Qaeda en el Magreb Islámico (AQMI), Al Qaeda, y grupos residentes en la península egipcia del Sinaí.

Por regiones podemos observar la existencia de diferentes vínculos entre organizaciones armadas africanas y las redes de Al Qaeda e ISIS - algunos de ellos efectivos, mientras que otros son exclusivamente nominales- (véase tabla 1). En la región del África Occidental, la presencia de Al Qaeda se establece principalmente a través de su rama local, Al Qaeda en el Magreb Islámico (Boeke, 2016; Laub y Masters, 2015; Filiu, 2009). Los orígenes de AQMI se remontan al argelino Grupo Salafista para la Predicación y el Combate (GSPC), fundado en 1998 por Hassam Hattab. En enero del año 2007 el GSPC modificó su nombre por Al Qaeda en el Magreb Islámico, aunque tres años antes ya le había declarado lealtad a la organización dirigida en aquel momento por Osama Bin Laden (Núñez, Hageraats, y Kotomska, 2009, p. 107). Posteriormente, una nueva ola de organizaciones armadas de carácter islámico nacería en la región al amparo de la desestabilización en el norte de Malí a finales de 2011. En diciembre de 2011, de la mano del líder tuareg maliense, Iyad Ag Ghali, emergerá la organización Ansar

\section{El surgimiento y la proliferación de ISIS habría alentado movimientos armados como el de Boko Haram}


Dine, quien desde sus orígenes ha mantenido una estrecha cooperación con AQMI. A partir del 2015, dos nuevos movimientos armados malienses se han asociado con Ansar Dine y por ende han fortalecido la presencia de la red dirigida por Ayman al-Zawahiri: Katiba Macina, activo en el centro de Mali y Katiba Khalid Ibn Walid, que opera en el sur del país (The Institute for Security Studies, 2016, p. 2)

La expansión de Al Qaeda en la región occidental del continente se vio debilitada momentáneamente debido a las diferentes escisiones internas producidas en el año 2012. En enero la primera escisión de AQMI dio a luz al Movimiento para la Unidad y Yihad en África Occidental (MUYAO), y a finales de ese mismo año, el histórico líder argelino, Mokhtar Belmokhtar, rompió con AQMI creando la organización Katiba al-Mulathemeen (Firmantes de Sangre). Ambas escisiones de la red de Al Qaeda se fusionaron posteriormente entre ellas, dando lugar al grupo conocido como Al Mourabitoune en mayo de 2013. Más adelante, en diciembre de 2015 AQMI y Al Mourabitoune anunciaron nuevamente su reunificación (Bogorad, 2016), hecho que pareció sellarse con la realización de diferentes atentados reivindicados conjuntamente por ambas organizaciones en Burkina Faso (15 y 16 enero) y Costa de Marfil (13 de marzo).

En este entramado estratégico de alianzas por el control de la región, un nuevo episodio se produjo el 2 de marzo de 2017, cuando se anunció la fusión de diferentes grupos yihadistas activos en la región del Sahel, con base en Mali, bajo una nueva formación autodenominada Jamaât Nasr Al islam wa Al mouminin (Grupo para el Apoyo del Islam y de los fieles). La fusión, cuyo liderazgo ha quedado bajo la figura de Iyad Ag Ghali, concierne la unión de Ansar Dine, Al Mourabitoune, Katiba Macina y AQMI. Días después de la fusión, el 19 de marzo Al Qaeda realizó un comunicado desde su sede central felicitando el surgimiento de la nueva alianza ${ }^{9}$. Esta última fusión se ha interpretado por un lado, como una mera formalización de los links ya existentes entre las diferentes organizaciones; mientras que por otro lado, se ha interpretado como una alianza que ha buscado contener la expansión de ISIS en la región, sobre todo debido a la presencia cada vez mayor de organizaciones como Islamic State in the Great Sahara (ISGS) -una escisión de Al Mourabitoune dirigida por Adnan Abu Walid al-Sahrawi, que opera sobre todo en la región de Liptako-Gourma (zona compartida entre Mali, Burkina Faso y Níger) ${ }^{10}$ - e Islamic State in West Africa -sobrenombre actual de Boko Haram-. Por otro lado, tampoco ha pasado desapercibido que la fusión se haya producido un mes después del anuncio de la creación de la fuerza militar regional G-5 Sahel, compuesta por tropas de Malí, Burkina Faso, Níger, Mauritania y Chad, y cuyo principal cometido es la lucha antiterrorista.

En la zona de la cuenca del Lago Chad, compuesta por la región noreste de Nigeria, el sur de Níger, el oeste de Chad y el norte de Camerún, la organización armada Boko Haram declaró su lealtad a Abu Bakr al-Baghdadi, líder del ISIS, en marzo de 2015, adoptando posteriormente el

8 "Jihadist Groups in The Sahel Region Formalize Merger", Jihadology, 27 de marzo de 2017 http://jihadology.net/2017/03/27/guest-post-jihadist-groups-in-the-sahel-region-formalize-merger/ [Consultado el 11 de abril de 2017].

9 Véase al respecto: New statement from al-Qā’idah's General Command: "Support and Blessing for Jamā’at Nuṣrat al-Islām Wa-l-Muslimīn”. 19 de marzo de 2017: http://jihadology.net/2017/03/19/new-statement-from-al-qaidahsgeneral-command-support-and-blessing-for-jamaat-nu\%el\%b9\%a3rat-al-islam-wa-l-muslimin/ [Consultado el 11 de abril de 2017].

10 El periódico francés Le Monde produjo una serie de seis artículos que detallan los ataques a principios de 2017 y la lucha contraterrorista en Burkina Faso. Disponible en: http://www.lemonde.fr/afrique/article/2017/04/09/leburkina-faso-a-l-epreuve-du-terrorisme_5108561_3212.html [Consultado el 16 de abril de 2017].

\section{La lucha}

antiterronista es el principal cometido de la fuerza militar regional G-5 Sahel, compuesta por tropas de Malí, Burkina Faso, Míger, Mauritania y Chad 
sobrenombre de Islamic State in West Africa ${ }^{11}$. Sin embargo, el reemplazo decretado por ISIS en el liderato del grupo a finales de 2016 de Abubakar Sekau por Abu Musab al-Barnawi, hijo del fundador de la organización Mohammed Yusuf (asesinado mientras se encontraba bajo custodia de las fuerzas policiales nigerianas en 2009), habría abierto la posibilidad de que una de las facciones buscase nuevas alianzas con Al Qaeda ante la creciente división interna (Burke, 2016). De hecho, con la red dirigida por al-Zawahiri, ya se habría vinculado en el año 2012 otro grupo armado nigeriano denominado Ansaru - una escisión de Boko Haram que no compartía los métodos de guerra de Sekau contra los musulmanes-.

En la región del África del este y el Cuerno de África, la organización armada somalí al-Shabaab mantiene largos vínculos con Al Qaeda desde el año 2009, y en los últimos años ha manifestado una hostilidad creciente contra la presencia de ISIS en la zona y sus esfuerzos por lograr asentarse en ella. Durante el año 2015, se produjeron en el interior de al-Shabaad diferentes escisiones que debilitaron a la organización, provocando purgas y ejecuciones internas ${ }^{12}$. Boko Haram y la propia ISIS en Siria e Iraq hicieron llamamientos al grupo a unirse a la organización dirigida por al-Baghdadi ${ }^{13}$. La penetración de ISIS en la región oriental africana fue una realidad a partir del 2015 con la conformación de diferentes organizaciones escindidas de al-Shabaab: el grupo Islamic State in Somalia, dirigido por Abdulqadr Mumin, vinculado con ISIS desde octubre de $2015^{14}$; o la posteriormente creada Jahba East Africa ${ }^{15}$, organización que comunicó su lealtad a ISIS el 7 de abril de 2016, cuestionando el liderazgo de al-Shabaab ${ }^{16}$.

11 Véase al respecto: "Nigeria’s Boko Haram pledges allegiance to Islamic State", BBC, 7 de marzo 2015: www.bbc. com/news/world-africa-31784538 [consultado el 31 de julio de 2015].

12 The Guardian, "Tensions rise as al-Shabaab foreign fighters consider supporting Isis", The Guardian, 8 de diciembre de 2015. https:/www.theguardian.com/world/2015/dec/08/american-us-resident-islamic-extremistsdefect-somalia-al-shabab [Consultado el 05 de abril de 2017].

13 Hiraan Online, "Come and join the caliphate, ISIS urges Al-Shabab" y "Join ISIS - Nigeria’s Boko Haram tells Al-Shabab", Hiraan Online, 4 y 15 de octubre de 2015, respectivamente: https:/www.hiiraan.com/news4/2015/ oct/101916/come_and_join_the_caliphate_isis_urges_al_shabab.aspx ; https://www.hiiraan.com/news4/2015/ oct/102107/join_isis_nigeria_s_boko_haram_tells_al_shabab.aspx [Consultado el 05/04/2017].

14 Para más información, véase https://www.trackingterrorism.org/group/jahba-east-africa-islamic-state-isis-somaliakenya-tanzania-and-uganda [Consultado el 05 de abril de 2017].

15 Para más información sobre Jahba East Africa, véase http://jihadology.net/category/jahba-east-africa/ [Consultado el 05 de abril de 2017].

16 Véase declaración de lealtad de Jahba East Africa a ISIS: https://azelin.files.wordpress.com/2016/04/jahbaeast-africa-22our-pledge-of-allegiance-to-the-shaykh-abucc84-bakr-al-baghdacc84dicc8422.pdf y http://www. centerforsecuritypolicy.org/2016/04/12/jahba-east-africa-jihadists-encroaching-upon-al-shabaab/ [Consultado el 13 de febrero de 2017].

\section{La penetración de ISIS en la región oriental africana fue una realidad a partir del 2015}


Tabla 1. Principales organizaciones yihadistas africanas y supuesta vinculación con ISIS o Al Qaeda a principios de 2018

\begin{tabular}{|c|c|c|c|c|}
\hline \multirow{2}{*}{ Nombre del grupo } & \multirow{2}{*}{$\begin{array}{l}\text { Área de actuación } \\
\text { principal }\end{array}$} & \multicolumn{2}{|c|}{ Vinculación supuesta } & \multirow{2}{*}{$\begin{array}{l}\text { Fecha vínculo } \\
\text { conocida }\end{array}$} \\
\hline & & Al Oaeda & ISIS & \\
\hline \multicolumn{5}{|l|}{ Norte de África } \\
\hline $\begin{array}{l}\text { Ansar al-Sharia (Facciones de Túnez y Libia - Benghazi } \\
\text { y Derna) }\end{array}$ & Túnez y Libia & $x$ & & 2011 \\
\hline Okba ibn Nafaa Brigade & Túnez & $x$ & & $s / d$ \\
\hline $\begin{array}{l}\text { Soldiers of the Caliphate } \\
\text { (También conocido como Jund al Khilafah) }\end{array}$ & Túnez & & $x$ & $s / d$ \\
\hline $\begin{array}{l}\text { Wilayat Barqa - Fezzan - Tarabulus } \\
\text { (Antes Shura Council of Islamic Youth) }\end{array}$ & Libia & & $x$ & $s / d$ \\
\hline Ajnad Misr & Egipto & $x$ & & $s / d$ \\
\hline $\begin{array}{l}\text { Islamic State-Sinai } \\
\text { (Antes Ansar Bayet al-Maqdis, ABM) }\end{array}$ & Egipto & & $x$ & Nov. 2014 \\
\hline \multicolumn{5}{|l|}{ Franja Sahel occidental } \\
\hline Al Qaeda en el Magreb Islámico (AOMI) & Sahel occidental & $x$ & & 2007 \\
\hline Ansar Dine & Mali & $x$ & & 2012 \\
\hline al-Morabitoum & Sahel occidental & $x$ & & Dic. 2015 \\
\hline $\begin{array}{l}\text { Macina Liberation Front (Front de Libération du } \\
\text { Macina o Katiba Macina) }\end{array}$ & Sahel occidental & $\begin{array}{l}\text { Alianza con } \\
\text { Ansar Dine }\end{array}$ & & $\begin{array}{l}\text { Principios de } \\
\quad 2015\end{array}$ \\
\hline $\begin{array}{l}\text { Islamic State in the Great Sahara (ISGS) } \\
\text { (Escisión de al-Morabitoum) }\end{array}$ & $\begin{array}{l}\text { Liptako-Gourma } \\
\text { región }\end{array}$ & & $x$ & Mayo 2015 \\
\hline $\begin{array}{l}\text { Jama'at Nusrat al-Islam wal Muslimeen } \\
\text { (Grupo de apoyo al islam y los musulmanes) }\end{array}$ & Sahel occidental & $x$ & & Marzo 2017 \\
\hline $\begin{array}{l}\text { Ansarul Islam } \\
\text { (Grupo surgido de MUYAO) }\end{array}$ & $\begin{array}{l}\text { Norte de Burkina } \\
\text { Faso y este de Malí }\end{array}$ & $\begin{array}{l}\text { Vínculos con } \\
\text { Katiba Macina }\end{array}$ & & $s / d$ \\
\hline \multicolumn{5}{|l|}{ Nigeria y Cuenca del Lago Chad } \\
\hline $\begin{array}{l}\text { Boko Haram } \\
\text { (Nombre oficial: Ahllissunah Wal Lidda'awati Jihad) }\end{array}$ & $\begin{array}{l}\text { Cuenca del Lago } \\
\text { Chad }\end{array}$ & & $x$ & Marzo 2015 \\
\hline $\begin{array}{l}\text { Ansaru } \\
\text { (Nombre oficial: Jamaatu Ansarul Muslimina Fi } \\
\text { Biladissudan (Escisión de BH)) }\end{array}$ & Nigeria & $\begin{array}{l}\text { Vínculos con } \\
\text { AQMI }\end{array}$ & & 2012 \\
\hline \multicolumn{5}{|l|}{ África del este } \\
\hline $\begin{array}{l}\text { al-Shabaab } \\
\text { (Nombre oficial: Harakat al-šabāb a-muŷahidīn) }\end{array}$ & Somalia & $x$ & & $\begin{array}{l}\text { Septiembre } \\
2009\end{array}$ \\
\hline $\begin{array}{l}\text { Jahba East Africa } \\
\text { (Escisión de al-Shabaab) }\end{array}$ & $\begin{array}{l}\text { Kenia, Tanzania, } \\
\text { Uganda, Somalia }\end{array}$ & & $x$ & 7 de abril 2016 \\
\hline $\begin{array}{l}\text { Islamic State in Somalia } \\
\text { (Escisión de al-Shabaab) }\end{array}$ & Somalia & & $x$ & $\begin{array}{l}\text { Octubre de } \\
2015\end{array}$ \\
\hline $\begin{array}{l}\text { Al Hijra } \\
\text { (Antes Muslim Youth Center) }\end{array}$ & Kenia & $\begin{array}{l}\text { Vínculos con } \\
\text { al-Shabaab }\end{array}$ & & Enero 2012 \\
\hline $\begin{array}{l}\text { Al Muhajiroun } \\
\text { (También conocido como Emigrants of East Africa) }\end{array}$ & Kenia & $\begin{array}{l}\text { Vínculos con } \\
\text { al-Shabaab }\end{array}$ & & $s / d$ \\
\hline Ansaar Muslim Youth Center (AMYC) & Tanzania & $\begin{array}{l}\text { Vínculos con } \\
\text { al-Shabaab }\end{array}$ & & $s / d$ \\
\hline
\end{tabular}

Fuente: Elaboración propia con datos del ICG (2016a), Africa Center (2018 y 2017) y otras fuentes periodísticas. (Nota: s/d: $\sin$ datos) 


\subsection{Despliegue de estrategias antiterroristas en el continente}

La creciente presencia y expansión de organizaciones armadas de carácter yihadista en el continente africano ha dado pie al despliegue de diferentes estrategias regionales de corte antiterrorista. Particularmente importante han sido las respuestas externas a la identificada como mayor amenaza terrorista en el continente: la región del Sahel (Harmon, 2015; Núñez, Hageraats y Kotomska, 2009). Esta respuesta ha estado encabezada principalmente por los Estados Unidos y Francia, y ha sido sobre todo de carácter militar, aunque también se han implicado otros actores de la comunidad internacional, entre los que podemos resaltar la Organización de las Naciones Unidas (ONU), la Unión Europea (UE), China o la propia Unión Africana (UA).

En el África Occidental, los EE. UU. llevan más de dos décadas implicándose en actividades de tipo militar, destacando su participación en programas como la African Crisis Response Iniciative (ACRI), la Operation Focus Relief (OFR) y la Global Peace Operations Iniciative (GPOI). En todas ellas, las operaciones se dirigían al entrenamiento de las fuerzas africanas para operaciones de mantenimiento de la paz, y no tenían un carácter específicamente contraterrorista. Sin embargo, su política en el continente africano sufrió una gran modificación a partir del 11-S (Harmon, 2015, p. 230). Es bastante significativo señalar cómo antes de los atentados en suelo estadounidense, los Estados Unidos no tenían reconocida a ninguna organización terrorista en el África subsahariana (Turse, 2015, p. 22). La primera operación específicamente de tipo antiterrorista surgió en el año 2002 con la puesta en marcha de la Pan-Sahel Initiative (PSI, 2002-2004) -bajo el mando de EUCOM ${ }^{17}$ - como respuesta a la amenaza yihadista en la región del Sahel. Posteriormente se amplió llamándose Trans-Saharan Counterterrorism Partnership (TSCTI), cuyo objetivo declarado ha sido la formación y asistencia a tropas de Malí, Níger, Chad y Mauritania y después ampliada a Nigeria, Senegal, Marruecos, Argelia y Túnez (Turse, 2015, p. 23).

Posteriormente, EE. UU. desplegó el AFRICOM (US Africa Command) en el año 2003, con la instalación de la base estadounidense Camp Lemonnier en Yibuti, la cual contaba con 2.000 soldados estadounidenses y cuya misión inicial se concentró en asistir en las capacidades de defensa de los países en el este de África, en la denominada Combined Join Task Force-Horn of África (CJTF-HOA) ${ }^{18}$. Desde ese momento, el investigador Nick Turse (2015, pp. 12-13) afirma cómo los EE. UU. han ubicado un buen número de bases militares en África -aunque solo se reconocía oficialmente la de Yibuti- y han intervenido militarmente en diferentes momentos y lugares del continente. El foco ha sido puesto en el desarrollo de operaciones contra grupos armados caracterizados como una mayor amenaza: AQMI; los movimientos islamistas en la región del Sahel -principalmente en Malí, como Ansar al-Dine-; Boko Haram; grupos vinculados a Al Qaeda y el autodenominado Estado Islámico en la Libia post-Gadafi; el Lord Resistance Army (LRA); al Shabaab; y los grupos vinculados a Al Qaeda en la Península Arábica que operan en el Golfo de Adén, Yemen (muy cerca de tierras somalíes) (Turse, 2015, p. 36).

En el año 2006, el Departamento de Estado de EE. UU. estableció una misión conjunta con la UA, para apoyar en el desarrollo de la African Standby Force (Fuerza Africana de Emergencia) como una fuerza multinacional de mantenimiento de la paz compuesta por tropas regionales con capacidad de movilizar entre 15.000 y 20.000 efectivos (Rye Olsen, 2015, p. 232).

\section{Las respuestas} externas

han estado

encabezadas

principalmente por Estados Unidos y Francia

17 Mando militar estadounidense para Europa y África.

18 Fuerza naval estadounidense encargada de combatir la piratería en aguas somalíes. 
Por otro lado, la Unión Europea también ha contribuido con el despliegue de iniciativas de seguridad en el marco de estrategias antiterroristas en el continente africano. En diciembre de 2008 puso en marcha en las costas somalíes del Golfo de Adén (Océano Índico), la llamada Operación Atalanta, bajo mandato de la EU Naval Force (EU-NAVFOR), cuyo objetivo era prevenir la piratería (Rye Olsen, 2015, pp. 236-237). La defensa del despliegue de la EU-NAVFOR ante el Consejo de Seguridad de Naciones Unidas le correspondió a Francia, país que lanzó posteriormente diferentes intervenciones unilaterales en el continente africano. El país galo puso en marcha en enero de 2013 la Operación Serval en Malí para ayudar a las fuerzas africanas del oeste desplegadas en el país, la African-led International Support Mission in Mali (AFISMA), dirigida a contener el avance de los movimientos yihadistas que se habían hecho con el control de la región septentrional del país. La operación logró retener el avance de los grupos yihadistas, así como expulsarlos de las ciudades que controlaban en el norte (Gao, Kidal y Tombuctú), aunque no logró su completa eliminación. La operación militar francesa en Malí acompaña otra operación bajo el mando de la Unión Europea, la European Union Training Mission -EUTM- que, conjuntamente con tropas estadounidenses, llevan a cabo programas de entrenamiento de las fuerzas nacionales de seguridad. Posteriormente, en 2014, la Operación Serval se reconvirtió en la Operación Barkhane y se amplió a otros países de la región, en lo que significó la transformación de una campaña de contrainsurgencia en Malí en una operación mayor de lucha antiterrorista prolongada en toda la región del Sahel (Mauritania, Malí, Burkina Faso, Níger y Chad). A su vez, las tropas francesas también están presentes en la República Centroafricana bajo el mandato de la Operación Sangaris.

La propia Unión Africana, en respuesta a las amenazas terroristas transnacionales, adoptó en 1999 la Convención de la OUA sobre Prevención y Lucha contra el Terrorismo y sus Protocolos Conexos, que entró en vigor en diciembre de 2002, y en la cual se comprometió a "eliminar el terrorismo en todas sus formas y manifestaciones" ${ }^{19}$. En la actualidad la UA, así como otros organismos o alianzas regionales del continente, además de participar en diferentes misiones cuyo mandato es el mantenimiento de la paz, está inmersa en diferentes iniciativas centradas en la de contención del terrorismo, de las cuales podemos destacar las siguientes:

» Somalia. Si bien la African Mission in Somalia (AMISOM), creada por el Consejo de Paz y Seguridad de la UA (African Union Peace and Security Council, AU-PSC) en enero de 2017, tenía como objetivo principal apoyar el establecimiento del Gobierno de transición, con el paso del tiempo ha transformado sus objetivos para implicarse de manera activa en operaciones ofensivas contra actores armados, realizando acciones antiterroristas y combatiendo principalmente a al-Shabaab ${ }^{20}$. En la actualidad, la fuerza del personal uniformado de la AMISOM está compuesta por 22.126 unidades (incluye tanto a las tropas militares como a fuerzas policiales), y su mayor parte procede de seis países: Uganda, Burundi, Yibuti, Kenia, Etiopía y Sierra Leona ${ }^{21}$.

» África Central. El 22 de noviembre de 2013 el AU-PSC autorizó el despliegue de la AU-Regional Cooperation Initiative for the Elimination of the Lord's Resistance Army (AURCI-LRA), declarando a su vez al LRA ugandés como organización terrorista. El desplie-

\section{La Unión Europea también ha contribuido con el despliegue de iniciativas de seguridad}

19 OUA, "OAU Convention on the Prevention and Combating of Terrorism", l de julio de 1999: https://www.au.int/ en/treaties/oau-convention-prevention-and-combating-terrorism

20 "The African Standby Force beyond 2015: ideals versus realities", ISS Today, 14 de septiembre de 2015.

21 Para mayor detalle sobre AMISOM, véase web oficial http://amisom-au.org/ 
gue de la RCI-LRA se justificó para acabar con la insurgencia dirigida por Joseph Kony debido a sus consecuencias humanitarias, así como por la amenaza que representaba para la seguridad y la estabilidad regional. La RCI poseía una Regional Task Force (RTF) con un componente militar límite autorizado de 5.000 efectivos aportados por los países afectados: Uganda, R. D. Congo, RCA y Sudán del Sur ${ }^{22}$. La iniciativa ha estado apoyada desde el año 2010 por Fuerzas Especiales de los Estados Unidos, aunque en marzo de 2017 se informó que este apoyo estaba llegando a su fin debido a la "irrelevancia" del LRA en la actualidad.

» Cuenca del Lago Chad. La expansión de la acción de Boko Haram por la Cuenca de Lago Chad generó la respuesta militar conjunta de los países de la región. En el marco de la Lake Chad Basin Commission (LCBC) y de su fuerza regional creada en marzo de 1994, la Multinational Joint Security Force, los países miembros y Benín ampliaron su mandato en abril de 2012 para combatir a la insurgencia de Boko Haram y renombraron en octubre de 2014 la fuerza regional como Multinational Joint Task Force (MNJTF). Durante el 2015 la MNJTF, con sede en N’Djamena (Chad), empezó a estar operativa bajo el amparo de la UA, compuesta inicialmente por 8.700 tropas de Níger, Nigeria, Chad, Camerún y Benín, facilitando a los ejércitos de los países miembros la incursión transfronteriza.

» Región Sahel oriental. Tras el fin de la operación francesa Serval en Malí en 2013 se conformó el grupo conocido como G-5 Sahel, compuesto por Burkina Faso, Malí, Níger, Chad y Mauritania, con sede en Nouakchott, Mauritania. El G-5 Sahel fue creado con el objetivo declarado de coordinar las acciones de lucha contra el terrorismo y garantizar la seguridad y el desarrollo en la región. En febrero de 2017, los jefes de Estado del G-5 Sahel decidieron aumentar la cooperación anunciando la creación de una Fuerza Militar Conjunta del Sahel G5, misma que fue aprobada por el AU-PSC en abril de 2017, quien autorizó un despliegue máximo de 5.000 unidades (incluyendo militares, policías y civiles) ${ }^{23}$. La Fuerza fue posteriormente respaldada por el Consejo de Seguridad de la ONU y cuenta con el apoyo de una variedad de socios internacionales.

» Liptako-Gourma Region. Otra de las recientes iniciativas regionales de lucha antiterrorista ha sido la creación por parte de Malí, Burkina Faso y Níger, de la Liptako-Gourma Region Joint Task Force (JTF), creada al amparo de la Integrated Development Authority of the Liptako-Gourma Region (ALG) ${ }^{24}$ el 24 de enero de 2017. La fuerza regional, que tiene un carácter similar al de la MNJTF (transfronterizo), se ha justificado debido al creciente riesgo y desestabilización de la región por parte de grupos armados de corte yihadista, principalmente la presencia de grupos afiliados a ISIS y a AQMI25.

22 African Union (2015) "The African Union-Led Regional Task Force for the elimination of the LRA", African Union Peace and Security, última actualización 23 de noviembre de 2015 http://www.peaceau.org/en/page/100-au-led-rcilra-1 [Consultado el 13 de abril de 2017].

23 Peace and Security Council, 679 th Meeting, Addis Abeba, Ethiopia, 13 de abril de 2017 http://www.peaceau.org/ uploads/679th-com-g5sahel-13-04-2017.pdf [Consultado el 18 de abril de 2017]

24 La Autoridad de Desarrollo Integrado de la Región de Liptako-Gourma (ALG, por sus siglas en inglés) fue creada el 3 de diciembre de 1970 en Ouagadougou (Burkina Faso) para promover el desarrollo armónico e integrado de la región de Liptako-Gourma. Sus miembros son Burkina Faso, Malí y Níger. La región de Liptako-Gourma, es un área de $370.000 \mathrm{~km}^{2}$ donde se sitúan, total o parcialmente, 19 provincias de Burkina Faso, cuatro regiones administrativas de Malí y dos departamentos y una comunidad urbana en Níger. En total representa el $45 \%$ de la población de los tres Estados.

25 La violencia en la región Liptako-Gourma aumentó significativamente tras el anuncio de la creación de la fuerza regional. Durante el mes de marzo de 2017 se produjeron diferentes ataques atribuidos sobre todo al autodenominado Ansarul Islam y a Jamaât Nasr Al islam wa Al mouminin.

El objetivo del G-5 Sahel es coordinar las acciones de lucha contra el terrorismo y garantizar la seguridad y el desarrollo en la región 


\subsection{Críticas a la narrativa del terrorismo y sus respuestas}

$\mathrm{Al}$ respecto de la narrativa del terrorismo y de las respuestas asociadas a esta, existen diferentes posturas críticas que han cuestionado, por un lado, los argumentos causales sobre los cuales se ha construido y, por otro, las medidas empleadas en su contención, basadas en la promoción de las respuestas militares y la cooperación en materia de seguridad. A su vez, bajo el discurso de la catalogación de grupos "terroristas" se ha justificado la premisa de la no negociación con este tipo de organizaciones, impidiendo de este modo la apertura de procesos de negociación de paz en aquellos contextos donde actúan. Este discurso también ha sido cuestionado por la criminalización de las rebeliones y la negación de otros elementos presentes en el origen de la violencia.

Uno de los puntos de partida de esta narrativa ha sido la correlación generada entre terrorismo y Estado fallido, sobre todo a raíz de los atentados del 11-S y los nuevos dilemas sobre la seguridad global que puso de relieve. En esta lógica se postula que el marco de este tipo de Estados se erige como la plataforma que da pie al surgimiento y proliferación de estos grupos. Sin embargo, autores como Newman (2007, pp. 483-484), cuestionan de lleno este vínculo afirmando al respecto:

There is not a conclusive relationship between state failure, weak states, and terrorism. Terrorists have a long history of operating within very different political and social environments [...]. When weak states coexist with other vulnerabilities -such as horizontal inequalities and inter-group conflict- then broader conflict is more likely and terrorism can be employed as a tactic in the context of such conflicts, usually locally.

Esta situación es sin duda aplicable a la realidad de muchos Estados en el África subsahariana, donde podemos encontrar diferentes contextos de capacidades estatales (Nigeria, Uganda, Somalia, Malí o Burkina Faso) sin que ello haya sido un elemento sine qua non que posibilite el surgimiento y desarrollo de grupos armados de estas características. Nigeria representa al respecto uno de los denominados países ancla del continente, sobre el cual se proyecta el crecimiento en la región del África Occidental; Uganda por su parte, ha sido bautizado como un modelo de reconstrucción posbélica en el continente a partir de 1986 y un ejemplo de liberación económica en el que se deberían reflejar los países africanos; Somalia por otro lado, es considerado, a raíz de 1993, como uno de los Estados más débiles del continente africano. Estas diferentes particularidades en cada uno de estos Estados no han evitado la emergencia de organizaciones extremistas violentas, por lo que la supuesta fortaleza o debilidad del Estado no ayuda a entender por qué surge y se despliega esta.

Por otro lado, la violencia de carácter islamista, en muchas ocasiones se ha presentado como una violencia de tipo completamente barbárico, construida sobre la base de la naturaleza inherentemente violenta del islam, tal y como había defendido Samuel Huntington (1993). Sin embargo, esta interpretación, además de conllevar una eminente carga culturalista y racista, dista mucho de poder explicar las causas del estallido de la violencia y, en último término, es incapaz de explicar por qué en otras sociedades con similar composición religiosa, la religión no provee la motivación para el estallido de la violencia. Existen otros factores en las causas que dan pie al estallido de la violencia política, donde la religión ha significado más un vehículo de canalización y discurso, que un motor para su estallido.

A este respecto, la investigadora del Instituto de Estudios del Desarrollo (IDS) Caitriona Dowd (2015b), cuestiona las explicaciones que postulan un vínculo entre la composición de las socie-
La religión ha significado más un vehículo de canalización y discurso, que un motor para el estallido de la violencia 
dades (tamaño absoluto y relativo de las poblaciones musulmanas en la sociedad) y la amenaza de violencia, ya sea a través de explicaciones socioculturales de las supuestas tendencias violentas del islam o a través de mecanismos demográficos asociados con el tamaño de la población, la competencia y la diversidad. Por el contrario, la violencia de carácter islamista no es diferente en sus orígenes y motivaciones que la presente en otro tipo de violencia política. Estos conflictos se deben interpretar en el marco de la exclusión política y los agravios presentes en las condiciones locales, que se relacionan con la marginalización política, la historia de violencia política presente en la región y su capitalización por parte de estos grupos, así como por su exclusión del aparato del Estado, (Dowd, 2015b, p. 505) poniendo de relieve la importancia de las condiciones sociales, económicas y políticas locales como motores de la violencia política y la violencia islamista específicamente. Una idea que Dowd (2015b, p. 195) resume de la siguiente manera: "Violent Islamist groups are highly contextualized, and emerge primarily in response to local drivers and conditions, often with local or national-level agendas." Una postura en la que también coincide Terje Østebø (2012, pp. 4-5) cuando señala: "While African Islamic militancy remains interlinked with broader ideological currents, it is clear that circumstances in local contexts have been important catalysts for its emergence and trajectory".

Jakkie Cilliers (2015a, p. 24) también incide en el impacto de los contextos externos y destaca diferentes causas que estarían detrás del auge de la violencia extremista en el continente africano:

Violent Islamist extremism has multiple causes. The explosive growth in recruitment and associated violence is because social, cultural, economic and political factors have come together in a perfect storm. These factors are primarily national, but cannot be separated from their regional and international contexts - nor from the appropriate historical contexts.

Herbst y Mills (2009, p. 32) además sostienen que existen diferentes fuerzas vinculadas -un gran número de Estados débiles, fronteras porosas, pobreza generalizada, frustración política y represión- cuya combinación se hace necesaria para crear "the kind of environment where alienation and radicalism should thrive”. En este sentido, señalan los autores (Herbst y Mills, 2009, pp. 32-34): "the conditions under which political Islam might be radicalised including corruption, state violence, the lack of social services, and an absence of political alternatives".

El caso del conflicto armado en la región del Sahel ha generado la percepción de ser un conflicto basado en las confrontaciones religiosas. Si bien la presencia de la religión es un hecho constatable, la rebelión del norte de Malí, para Grégory Chauzal y Thibault Van Damme (2015) ilustra, por un lado, las históricas tensiones existentes entre el norte y el sur del país, exacerbadas por la política colonial francesa del "divide y vencerás” y la política de instrumentalización identitaria orquestada desde el Gobierno de Bamako; y, por otro, las inequidades y agravios que el Estado maliense y sus élites políticas han generado en el país, concentrando el desarrollo al sur del río Níger e implementando una política basada en la coacción y la militarización en el norte. A su vez, en las causas iniciales de la rebelión árabe/tuareg coexisten otra multiplicidad de factores que Chauzal y Van Damme señalan imprescindibles para poder entender la complejidad del conflicto: el dominio de los pueblos del sur; las tensiones fronterizas y la permeabilidad de las fronteras; la estrategia de división y confrontación en las poblaciones norteñas por parte del Gobierno con el objeto de impedir la unidad y mantener fragmentado el norte; el desempleo, la pobreza y el descontento juvenil; el impacto de intereses externos;

Los conflictos se deben interpretar en el marco de la exclusión política y los agravios presentes en las condiciones locales 
la historia contemporánea de rebeliones de los pueblos árabes y tuaregs contra el Estado, que han generado cuatro insurrecciones desde la independencia nacional (1963-1964; 1990-1996; 2006-2009; 2012-2015).

Algo similar sucede con la insurgencia de Boko Haram en Nigeria, cuyo caso también es paradigmático de la presentación de un conflicto que hunde sus raíces y sus fines en el fundamentalismo religioso. La organización Boko Haram es presentada como un grupo islamista radical que lucha por imponer un califato (con una versión extrema de la sharia) en el norte de Nigeria, sin embargo, las motivaciones esgrimidas que dan origen al surgimiento de Boko Haram, según expone Roland Marchal (2012) tienen diferentes interpretaciones: una de ellas señala cómo la insurgencia hunde sus raíces en la marginalidad y el subdesarrollo económico de la región septentrional, en los agravios que los sucesivos regímenes nigerianos han generado frente a la población del norte; otra, la relaciona con la larga historia que presenta la región y la repetición de movimientos islamistas radicales; desde otra interpretación se asume que Boko Haram es un instrumento de las élites del norte como represalia frente a la progresiva pérdida de poder político, militar y administrativo que sus representantes han sufrido desde la independencia; y finalmente otras lecturas señalan los deseos de venganza contra el comportamiento de los organismos de seguridad y la represión del Gobierno central.

Precisamente este último aspecto es resaltado por Catriona Dowd (2015a, p. 523) para señalar cómo, además de los factores locales detonantes de la violencia propios de cada contexto relativos a la marginalidad y la exclusión, también existen evidencias que señalan que a todos ellos les une algún o algunos eventos en cada contexto particular, que sirven como detonantes para explicar el estallido y la escalada de violencia y que normalmente están relacionados con eventos de represión política por parte del aparato del Estado. Unos eventos que en ocasiones incluso, como denuncia Cilliers (2015a, p. 25) pueden ayudar a detonar la violencia a gran escala, tal y como han supuesto las intervenciones estadounidenses en diferentes contextos: "[w]ithout fail, US interventions in Afghanistan, Iraq, Syria, Libya and Somalia have exacerbated local situations and facilitated the spread of violent Islamist extremism”. Una crítica que también comparte Joseba Zulaika (2016, p. 22), quien aporta otro ejemplo al respecto de la intervención estadounidense en Iraq en marzo de 2003: "Era falso que Al Qaeda se hallaba en Iraq antes de marzo del 2003 (la excusa de Bush para ir a la guerra) pero luego ha sido verdad que Al Qaeda opera en Iraq tras la invasión americana, la misma organización que ha dado origen más tarde al Estado Islámico o ISIS”.

Esta realidad da pie para presentar otra de las importantes críticas hacia esta narrativa, que alude al tipo de respuestas desplegadas bajo su tutela y su efectividad, y que finalmente remiten a la edificación de la nueva doctrina de seguridad, cuyos resultados están lejos de lograr la contención del terrorismo. Más bien se ha producido un efecto completamente inverso. Una realidad sobre la que John Mueller (2006, p. 1) se pregunta: “¿Cuál es la amenaza mayor, el terrorismo, o la reacción al mismo?”.

Nick Turse (2015, p. 37) se hace eco de los resultados obtenidos a través de las numerosas misiones internacionales y la nueva arquitectura de seguridad construida en el continente africano a partir de 2001, las cuales no parece que estén teniendo, hasta la fecha, un impacto significativo en la reducción de la violencia. De manera específica, y en lo referente al despliegue del AFRICOM y la participación estadounidense en el continente, según Turse, los resultados no parecen haber sido muy positivos, para quien "after ten years of US operations to promote stabi-

\section{El surgimiento de Boko Haram hunde sus raíces en la marginalidad y el subdesarrollo económico de la región}


lity by military means, the results have been the opposite. África has become blowback central". Ello, a pesar de que el número de actividades del AFRICOM ha ido creciendo con el paso del tiempo, registrando en 2013, 546 actividades -lo que equivale a más de una misión y media por día- en al menos 49 de los 54 países del continente africano (Turse, 2015, pp. 73-78).

La crisis de Malí, producida a raíz de la rebelión tuareg en la región de Azawad en diciembre de 2012, puso también en duda la eficacia de los esfuerzos en la lucha contraterrorista de los EE. UU. Por un lado, el inicio de la rebelión tuareg está directamente relacionado con la caída del régimen de Gaddafi en Libia, que propició el surgimiento de numerosas milicias al interior del país, pero también expandió la guerra a otros rincones, fundamentalmente a la región del Sahel y a Malí. Por otro lado, el golpe de Estado que derrocó al gobierno maliense el 21 de marzo de 2012 fue liderado por Amadou Sanogo, un oficial que había recibido entrenamiento militar en EE. UU. entre los años 2004 y 2010 como parte de la Pan-Sahel Initiative (Turse, 2015, p. 28).

Si observamos los datos presentados por el National Consortium for the Study of Terrorism and Responses to Terrorism de la Universidad de Maryland en el Global Terrorism Database, en el año 2001 se habían registrado en África subsahariana un total de 119 incidentes terroristas, pero a partir del año 2004 el número de incidentes empezó a crecer, alcanzando el punto más alto en el año 2014, con casi 2.400 incidentes registrados (véase gráfico 1).

Gráfico 1. Incidentes terroristas registrados en la región de f́frica Subsahariana Incidents

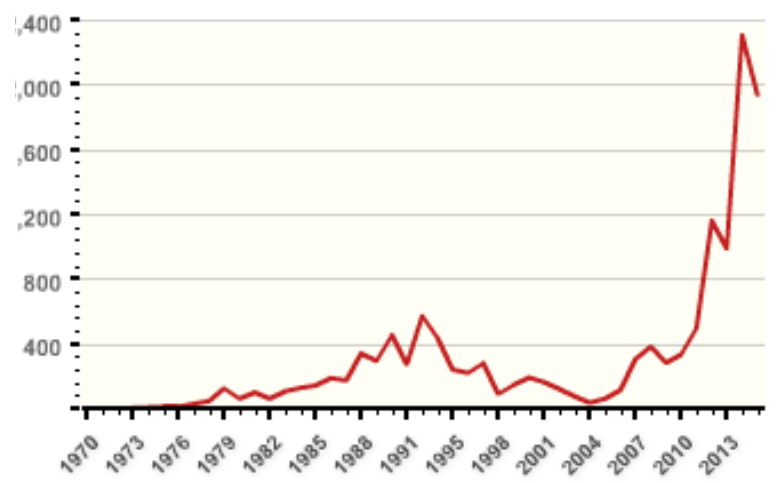

Fuente: Global Terrorism Database $e^{26}$

En ese año "que marcó un punto de inflexión por la enorme violencia padecida en diferentes conflictos armados producidos en distintas regiones del mundo- el Institute for Economics and Peace, en su informe 2015 Global Terrorism Index, -que hace alusión a la conflictividad del año anterior- señaló a la insurgencia de Boko Haram como el grupo más letal del mundo, con un total de 6.644 muertes que superaron las 6.073 registradas por parte de ISIS ${ }^{27}$. El año siguiente, y ya con el despliegue efectivo de la fuerza regional para combatir a Boko Haram en la

26 https://www.start.umd.edu/gtd/search/Results.aspx?region=11 [Consultado el 01 de noviembre de 2016].

27 The Institute for Economics and Peace, 2015 Global Terrorism Index, noviembre de 2015 
región de la Cuenca del Lago Chad (MNJTF), los datos registrados por el programa del Council on Foreign Relations, Nigeria Security Tracker (NST) documentaron un aumento de las cifras de víctimas, llegando a las 7.492 muertes producidas por el conflicto tan solo en los Estados norteños nigerianos de Borno, Adamawa, Yobe y Gombe ${ }^{28}$.

Turse (2015, p. 31) también denunciaba el impacto negativo de la participación estadounidense en el caso de Nigeria, donde después de años de asistencia y formación militar realizada por el ejército estadounidense, a través del programa denominado Africa Contingency Operations Training and Asistance, no ha servido para evitar los abusos cometidos por el ejército nigeriano que, entre otros resultados, trajo la transformación de la secta islámica Boko Haram en una fuerza regional terrorista. El papel de las fuerzas de seguridad nigerianas y las violaciones a los derechos humanos y los crímenes cometidos por estas en diferentes regiones del país, también fue denunciado por la ONG Amnistía Internacional (2015). La ONG evidenció que en el año 2015 las fuerzas armadas nigerianas cometieron crímenes de guerra y posibles crímenes contra la humanidad en su respuesta a la insurgencia de Boko Haram entre los años 2011 y 2015 , periodo en el cual alrededor de 7.000 hombres y menores habrían resultado muertos cuando se encontraban bajo detención militar. Ante las sistemáticas violaciones a los derechos humanos en el país, la organización International Crisis Group (2016b) postulaba como uno de los mayores desafíos para Nigeria la realización de una reforma integral de su sector de seguridad que incida en su profesionalización, eficacia, rendición de cuentas y respeto por los derechos humanos, para reducir el factor de riesgo que hoy en día representa la mala praxis de los cuerpos de seguridad.

Du Plessis y Allison (2017) argumentan que existen diferentes razones para explicar la realidad generalizada del fracaso de las políticas contraterroristas en el continente, resaltando como la más significante de todas ellas la priorización dada a la respuesta militar y de securitización y la vulneración de derechos y la represión social que en ocasiones la ha acompañado y que ha generado, como en el caso de la sufrida a manos de la organización islámica Boko Haram en julio de $2009^{29}$, su transformación de "un grupo islámico peligroso pero moderado a una organización militante radical”.

Por otro lado, y como señalábamos anteriormente, en el marco de estas políticas de securitización y predominio de las respuestas militares, se ha excluido cualquier tipo de negociación de paz con los grupos categorizados bajo el perfil de "extremismo yihadista". La lectura de que frente al terror no hay ninguna posibilidad de diálogo, esconde las causas principales que están detrás de estas rebeliones e imposibilita su resolución política. Al respecto, el ejemplo de Malí es ilustrativo de esta tendencia. La firma del Acuerdo de Paz de Argel en junio de 2015 entre el Gobierno maliense y los principales movimientos rebeldes de corte árabe-tuareg a quienes sí se concede agencia política a través de la Coordinadora de Movimientos de Azawad (CMA), aglu-

28 Sin embargo, también hay que resaltar que durante el año 2016 la estrategia de la MNJTF parece que ha empezado a dar algunos resultados, logrando arrebatar a la insurgencia importantes franjas de territorio, lo que por un lado ha reducido significativamente su capacidad e impacto en la región mientras que, por otro lado, ha aumentado el empleo de ataques suicidas contra la población civil como modus operandi de Boko Haram. A su vez, la estrategia militar también ha logrado generar divisiones en el movimiento, que lo ha llevado a pugnas internas por el liderazgo entre Sekau y el jeque Abu Musab al-Barnawi.

29 Hace alusión a la represión llevada a cabo por las fuerzas de seguridad contra el movimiento de Boko Haram en julio del 2009, que se saldó con la muerte de entre 400 y 800 personas en una semana de enfrentamientos en los estados de Borno, Yobe y Kano, y la detención y posterior ejecución en dependencias policiales de Mohammed Yussuf, el entonces líder de Boko Haram. Estos hechos dieron pie a que Boko Haram modificase sus métodos de lucha y pasara a la fase de lucha armada dirigida por Abubakar Sekau.

\section{La lectura de que} frente al terror no hay ninguna posibilidad de diálogo imposibilita su resolución política 
tinadora de los grupos que luchan por la independencia de la región de Azawad, y la Plataforma, coordinadora de los movimientos árabe-tuareg pro-unidad nacional, dejó fuera a los movimientos armados considerados de corte yihadista, ante los que el Estado maliense ha optado por dar una respuesta meramente militar. Como consecuencia, estos movimientos han intensificado los ataques y atentados desde la firma de la paz entre el Gobierno y los movimientos armados seculares, teniendo como objetivos prioritarios a las fuerzas internacionales, así como a los intereses extranjeros, extendiendo las acciones militares en diferentes países de la región.

\section{A modo de conclusión}

La narrativa del terrorismo se ha erigido en un discurso que ha seleccionado y reelaborado -como exponía Mark Duffield (2001, p. 148) en alusión a la tesis de las "nuevas guerras"aquellas verdades que le convienen a la hora de presentar una visión del mundo coherente y funcional, ocultando otras causas sin las cuales es imposible entender las raíces de la violencia. Este diagnóstico ha justificado las respuestas bajo el principio de la securitización, cuyos resultados obtenidos hasta la fecha, están lejos de proveer soluciones estables. Estas respuestas han diferido ostensiblemente de aquellas dadas a otros conflictos armados identificados en el continente africano que no han sido clasificados bajo el criterio de organizaciones terroristas. Ello se observa por ejemplo en la gestión de las crisis abiertas en la R. Centroafricana, Sudán del Sur, Sudán, Etiopía o R. D. Congo, donde las acciones regionales e internacionales se han basado en el despliegue de misiones de mantenimiento de la paz, la apertura de negociaciones de paz y no en la confrontación armada con los actores irregulares. En algunos de estos conflictos, como lo representan la R. Centroafricana, Sudán del Sur o Etiopía, las medidas adoptadas han logrado la firma de acuerdos de paz y la reducción significativa de la violencia -si bien no han puesto fin a la violencia-.

La complejidad de la conflictividad armada presente en el continente africano requiere de aproximaciones holísticas que superen la miopía de las miradas monocausales que tienden a ignorar las motivaciones políticas, el papel de los agravios, las fuerzas históricas o las dimensiones locales, regionales e internacionales como motores fundamentales del origen de las disputas, la confrontación y la violencia armada. A su vez, también se requiere de aproximaciones que huyan de las miradas universales sobre los orígenes de la erupción de la violencia armada, para tratar de entender el carácter particular que da pie al estallido de cada conflicto, su génesis y sus dinámicas. Las respuestas, por tanto, deberían partir de integrar múltiples niveles de análisis y, sobre todo, priorizar las actuaciones en la fase de prevención de los conflictos.

\section{Bibliografía}

Abbink, J., de Bruijn, M., y Van Walraven, K. (Eds.). (2008). A propósito de resistir. Repensar la insurgencia en África. Barcelona: Oozebap.

Africa Center for Strategic Studies. (2018). More Activity but Fewer Fatalities Linked to African Militant Islamist Groups in 2017. Recuperado de https://africacenter.org/spotlight/ activity-fewer-fatalities-linked-african-militant-islamist-groups-2017/

Africa Center for Strategic Studies. (2017). ISIS's Future in Africa after Iraq and Syria. Recuperado de http://africacenter.org/spotlight/isis-future-africa-iraq-syria/ 
Amnesty International. (2016). Nigeria: 'Bullets were raining everywhere. Recuperado de https:// www.amnesty.org.nz/nigeria-bullets-were-raining-everywhere

Amnesty International. (2015). Stars on their shoulders. Blood on their hands. War crimes committed by the Nigerian military. Recuperado de http://www.amnestyusa.org/research/ reports/stars-on-their-shoulders-blood-on-their-hands-war-crimes-committed-by-thenigerian-military

Bøås, M., \& Dunn, K. C. (Ed.). (2007). African Guerrillas. Raging Against the Machine. Lynne Rienner Publishers. Londres: Boulder.

Boeke, S. (2016). Al Qaeda in the Islamic Maghreb: Terrorism, insurgency, or organized crime? Small Wars \& Insurgencies, 27(5), 914-936. DOI: https://doi.org/10.1080/09592318.20 16.1208280

Bogorad, O. (2016). Local Networks Key to AQMI's West African Expansion. IPI Global Observatory. Recuperado de https://theglobalobservatory.org/2016/04/al-qaeda-islamicmaghreb-grand-bassam/

Botha, A. (2008). Terrorism in the Maghreb. Institute for Security Studies, 144.

Bruce, G. (2013). Definition of Terrorism Social and Political Effects. Journal of Military and Veterans' Health, 21(2), 26-30.

Burke, J. (2016). Isis an al-Qaida turf wars in Africa may push fragile states to breaking point. The Guardian. Recuperado de https:/www.theguardian.com/global-development/2016/ oct/06/isis-al-qaida-turf-wars-africa-may-push-fragile-states-to-breaking-point

Chauzal, G., \& Van Damme, T. (2015). The roots of Mali's conflict. Moving beyond the 2012 crisis. Clingendael. Recuperado de https://www.clingendael.nl/pub/2015/the_roots_of_ malis_conflict/

Cilliers, J. (2015a). Violent Islamist Extremism and Terror in Africa. Institute for Security Studies, 286.

Cilliers, J. (2015b). ¿Futuro (Im)Perfecto? Un mapa de los conflictos, la violencia y el extremismo en África. Institute for Security Studies, 287.

Cilliers, J. (2003). Terrorism and Africa. African Security Review, 12(4), 91-103. DOI: https:// doi.org/10.1080/10246029.2003.9627255

Clapham, C. (Ed.). (1998). African Guerrillas. Oxford: James Currey, Ltd. Indiana University Press y Fountain Publishers.

Collier, P., \& Hoeffler, A. (2004). Greed and Grievance in Civil War. Oxford Economic Papers, 56(4), 563-595. DOI: https://doi.org/10.1093/oep/gpf064

John, J. di. (2010). The Concept, Causes and Consequences of Failed States: A Critical Review of the Literature and Agenda for Research with Specific Reference to Sub-Saharan Africa. European Journal of Development Research, (22), 10-30. DOI: https://doi. org/10.1057/ejdr.2009.44

Dowd, C. (2015a). Grievances, governance and Islamist violence in sub-Saharan African. Journal of Modern African Studies, 53(4), 505-531. DOI: https://doi.org/10.1017/ S0022278X15000737 
Dowd, C. (2015b). Cultural and Religious Demography and Violent Islamist Groups in Africa. Political Geography, (45), 11-21. DOI: https://doi.org/10.1016/j.polgeo.2014.09.006

Du Plessis, A., \& Allison, S. (2017). How Africa can win the war on islamist militants. Newsweek. https://www.newsweek.com/africa-terrorism-islamist-boko-haram-al-shabab-aqim-569560

Duffield, M. (2001). Las nuevas guerras en un mundo global. La convergencia entre desarrollo y seguridad. Madrid: Los Libros de la Catarata.

Escola de Cultura de Pau. (2017). ¡Alerta 2016! Informe sobre conflictos armados, derechos humanos y construcción de paz. Barcelona: Editorial Icaria.

Filiu, J.-P. (2009). Al-Qaeda in the Islamic Maghreb: Algerian Challenge or Global Threat? Carnegie Endowment for International Peace. Washington, DC. Recuperado de http:// carnegieendowment.org/files/al-qaeda_islamic_maghreb.pdf

Forest, J., \& Giroux, J. (2011). Articles Terrorism and Political Violence in Africa: Contemporary Trends in a Shifting Terrain. Perspectives on terrorism, 5(3-4), 5-17.

Global Terrorism Database. National Consortium for the Study of Terrorism and Responses to Terrorism. University of Maryland. Recuperado de www.start.umd.edu/gtd

Harmon, S. (2015). Securitization Initiatives in the Sahara-Sahel Region in the Twenty-first Century. African Security, 8(4), 227-248. DOI: https://doi.org/10.1080/19392206.201 5.1100503

Herbst, J., \& Mills, G. (2003). Africa and the war on terror. South African Journal of International Affairs, 10(2). DOI: https://doi.org/10.1080/10220460309545425

Huntington, S. P. (1993). The clash of civilizations. Foreign Affairs, 72(3). DOI: https://doi. org/10.2307/20045621

International Crisis Group. (2016a). Exploiting Disorder: Al-Qaeda and the Islamic State. Crisis Group. Special Report 1, Jihad in Modern Conflict. Recuperado de https:/www. crisisgroup.org/global/exploiting-disorder-al-qaeda-and-islamic-state

International Crisis Group. (2016b). Nigeria: The challenge of Military Reform. Africa Report, 237.

Isaacman, A. (1977). Social Banditry in Zimbabwe (Rhodesia) and Mozambique, 1894-1907: An Expression of Early Peasant Protest. Journal of Southern African Studies, 4(1), 1-30. DOI: https://doi.org/10.1080/03057077708707977

Kaldor, M. (2001). Las Nuevas Guerras. La violencia organizada en la era global. Barcelona: Tusquets Editores.

Kaplan, R. (1994). The Coming Anarchy. How scarcity, crime, overpopulation, tribalism, and disease are rapidly destroying the social fabric of our planet. The Atlantic Monthly, February.

Keller, E. J. (1973). A Twentieth Century Model: The Mau Mau Transformation from Social Banditry to Social Rebellion. Kenya Historical Review, (1), 189-205.

Kepel, G. (2000). La yihad. Expansión y declive del islamismo. Barcelona: Ediciones Península. 
Laub, Z., \& Masters, J. (2015). Al-Qaeda in the Islamic Maghreb (AQMI). Council on Foreign Relations. CFR Backgrounders.

Maïga, I., \& Assanvo, W. (2017). Mali's jihadist merger: desperate or dangerous? Institute for Security Studies.

Marchal, R. (2012). Boko Haram and the resilience of militant Islam in northern Nigeria. NOREF Report, Nordic International Support Foundation.

Mazrui, A. (1985). The third world and international terrorism: Preliminary reflections. Third World Quarterly, 7(2), 348-364. DOI: https://doi.org/10.1080/01436598508419842

Melo, P. A. (2010). In search of new wars: The debate about a transformation of war. European Journal of International Relations, 16. DOI: https://doi.org/10.1177/1354066109350053

Milliken, J., \& Krause, K. (2002). State Failure, State Collapse, and State Reconstruction: Concepts, Lessons and Strategies. Development E Change, 3(5), 753-774. DOI: https:// doi.org/10.1111/1467-7660.t01-1-00247

Mueller, J. (2006). Overblown: How Politicians and the Terrorism Industry Inflate National Security Threats, and Why We Believe Them. Nueva York: Free Press.

Newman, E. (2007). Weak States, State Failure, and Terrorism. Terrorism and Political Violence, 19, 463-88. DOI: https://doi.org/10.1080/09546550701590636

Núñez Villaverde, J. A., Hageraats, B., \& Kotomska, M. (2009). Terrorismo internacional en África. La construcción de una amenaza en el Sahel. Madrid: Ediciones Catarata.

OAU, Convention on the Prevention and Combating of Terrorism, artículos 1.3 y 3.

Østebø, T. (2012). Islamic Militancy in Africa. Africa Security Brief, Africa Center for Strategic Studies, 23. DOI: https://doi.org/10.21236/ADA567188

Rapoport, D. C. (Ed.). (2006). Terrorism. Critical Concepts in Political Science. Routledge.

Rapoport, D. C. (2002). The Four Waves of Rebel Terror and September 11. Anthropoetics-The Journal of Generative Anthropology, VIII(1).

Reno, W. (2011). Warfare in independent Africa. Cambridge: Cambridge University Press. DOI: https://doi.org/10.1017/CBO9780511993428

Ruiz-Giménez Arrieta, I. (Ed.). (2012). Más allá de la barbarie y la codicia. Historia y política en las guerras africanas. Barcelona: Edicions Bellaterra.

Rye Olsen, G. (2015). 'Great power' intervention in African armed conflicts. Cambridge Review of International Affairs, 28(2), 229-245. DOI: https://doi.org/10.1080/09557571.2013.8 67299

Schmid, A. P. (2004). Frameworks for conceptualising Terrorism. Terrorism and Political Violence, 16(2). DOI: https://doi.org/10.1080/09546550490483134

Schmid, A. P., Jongman, A. J., Stohl, M., Brand, J., Fleming, P. A., Poel, A. van der, \& Thijsse, R. (1988). Political terrorism: A new guide to actors, authors, concepts, data bases, theories and literature. Transaction Books New Brunswick, NJ.

Sharif, T. A., \& Richards, J. (2016). Towards a continental strategy for countering violent extremism in Africa. Global Peace Operations Review, Annual Compilation. Recuperado 
de http://peaceoperationsreview.org/thematic-essays/towards-a-continental-strategy-forcountering-violent-extremism-in-africa/

Siegle, J., \& Williams, W. (2017). ISIS in Africa: implications from Syria and Iraq. Africa Center for Strategic Studies y National Defense university.

The Institute for Security Studies. (2016). Mali's young 'jihadists'. Fuelled by faith or circumstance? ISS Policy Brief, (89). Recuperado de https://issafrica.s3.amazonaws.com/site/ uploads/policybrief89-eng-v3.pdf

The Week UK. (2015). Islamic State, Daesh or Isis: the dilema of naming the militants. 13 de julio de 2015. Recuperado de http://www.theweek.co.uk/islamic-state/62422/islamicstate-daesh-or-isis-the-dilemma-of-naming-the-extremists

Tilly, C. (2004). Terror, Terrorism, Terrorist. Sociological Theory, 22(1), 5-13. DOI: https://doi. org/10.1111/j.1467-9558.2004.00200.x

Turse, N. (2015). Tomorrow's Battlefield. US Proxy Wars and Secret Ops in Africa. Chicago: Haymarket Books.

Walraven, K. van, Bruijn, M. de, \& Abbink, J. (Eds.). (2008). A propósito de resistir. Repensar la insurgencia en la historia africana. Barcelona: Oozebap.

Zulaika Irureta, J. (2016). El mapa y el territorio: Cuestiones ontológicas y epistemológicas sobre el terrorismo. Relaciones Internacionales, (32), 15-32. 